\title{
Loss of interleukin-6 enhances the inflammatory response associated with hyperoxia-induced lung injury in neonatal mice
}

\author{
HENGTAO LI $^{1 *}$, GENZAI WANG $^{1 *}$, SHUZHU LIN $^{1}$, CHUNYAN WANG $^{1}$ and JIANZHONG ZHA ${ }^{2}$ \\ ${ }^{1}$ Department of Pediatrics, Fengcheng Hospital, Shanghai 201411; ${ }^{2}$ Department of Pediatrics, \\ Ninth People's Hospital, Shanghai Jiaotong University School of Medicine, Shanghai 200011, P.R. China
}

Received March 12, 2018; Accepted December 21, 2018

DOI: $10.3892 /$ etm.2019.7315

\begin{abstract}
In bronchopulmonary dysplasia (BPD), decreased angiogenesis and alveolarization is associated with pulmonary cell death and inflammation. It is commonly observed in premature infants who required mechanical ventilation and oxygen therapy. Since enhanced interleukin-6 (IL-6) expression has been reported in infants with BPD, it was hypothesized that a decrease in IL-6 may enhance lung inflammation and decrease hyperoxia-induced neonatal lung injury in mice. In the current study, newborn wild-type (WT) and IL-6 null mice were treated with $85 \% \mathrm{O}_{2}$ (hyperoxia) or $21 \% \mathrm{O}_{2}$ (normoxia) for $96 \mathrm{~h}$. Although the increased volume and decreased quantity of alveoli was triggered by hyperoxia in WT and IL-6 null mice, transcription and translation of proinflammatory cytokines (monocyte chemoattractant protein-1, IL-10, IL-12 and tumor necrosis factor- $\alpha$ ) and pulmonary cell death (caspase stimulation and terminal deoxynucleotidyl-transferase-mediated dUTP nick end labeling staining) were significantly enhanced in IL-6 null mice compared with WT mice. These results suggest that the crosstalk between inflammation and cell death may be involved in hyperoxia-induced lung injury in BPD. Future treatment approaches for bronchopulmonary dysplasia should be based on the suppression of cytokine expression.
\end{abstract}

\section{Introduction}

Bronchopulmonary dysplasia (BPD) is a chronic lung disease commonly observed in premature infants and a major contributor to long-term morbidity and mortality in premature infants (1). The pulmonary inflammatory response induced by mechanical ventilation (MV) and oxygen toxicity (OT) is crucial to the pathogenesis of BPD, which is demonstrated by

Correspondence to: Dr Genzai Wang, Department of Pediatrics, Fengcheng Hospital, 9983 Chuannanfeng Highway, Fengxian, Shanghai 201411, P.R. China

E-mail: wanggenzai@163.com

*Contributed equally

Key words: interleukin-6, inflammatory, hyperoxia, lung apoptosis an induction of proinflammatory cytokines and an enhanced influx of neutrophils and macrophages (2-4). Upregulation of pro-inflammatory cytokines, which include interleukin (IL)-1 $\beta$, IL-8, IL-6 and tumor necrosis factor (TNF)- $\alpha$ are associated with the development of BPD (5). By contrast, patients with BPD exhibited a decreased expression of anti-inflammatory cytokines and growth factors, which include PDGF-A and VEGF-A, which are essential to angiogenesis and alveolar development $(6,7)$.

IL-6 can activate various signaling cascades and is involved in several processes, which include bone remodeling, acute inflammation, cellular proliferation, differentiation and cell death $(8,9)$. Previous studies investigating the potential functions of IL- 6 demonstrated the importance of IL- 6 signaling in the development of the submandibular gland $(10,11)$, mammary gland remodeling (12), normal prostate development and prostate malignancy (13), and pulmonary maturation (14). Although the amniotic fluid concentration of IL-6 was significantly increased in mothers whose premature infants acquired BPD (5), the functional role of IL-6 in the development of BPD remains unknown.

Oxygen-induced lung injury is a known risk factor associated with the development of BPD (15). High and prolonged oxygen exposure in newborn rodents is commonly used to study the effect of hyperoxia in lung development (16). Hyperoxic lung injury (HLI) is initiated by increased levels of reactive oxygen species, which is followed by the secretion of proinflammatory chemokines and cytokines by resident macrophages and epithelial cells (17). The aim of the current study was to investigate the effect of genetic ablation of the IL- 6 gene on the inflammatory response of HLI in newborn mice.

\section{Materials and methods}

Animals and neonatal hyperoxic exposure. Mice homozygous for the IL-6 null mutation (total number, 30; age, 4-6 weeks) and corresponding wild-type (WT) littermates (total number, 30; age, 4-6 weeks) were obtained from The Jackson Laboratory (Bar Harbor, ME, USA; all C57BL/6 mice; weight, 20 g; sex ratio, 1:1). All mice were housed in separate cages under controlled temperature $\left(21 \pm 1^{\circ} \mathrm{C}\right)$ and humidity $(35 \pm 5 \%)$ condition with a 12-h light/dark cycle and access to food and water ad libitum. C57BL/6 newborn mice were randomized into either hyperoxia $\left(85 \% \mathrm{O}_{2}\right)$ or normoxia (normal air) groups for $<24 \mathrm{~h}$ 
following birth, followed by normoxia conditions for all animals for the subsequent 4 days. Nursing mice were changed every day between hyperoxia and normoxia groups to decrease the toxic effect of oxygen in maternal mice. All animal experiments were performed at the Fengcheng Hospital (Shanghai, China) according to the Animal Use Committee of Fengcheng Hospital.

Lung tissue collection. Mice were anesthetized via intraperitoneal injection of $50 \mathrm{mg} / \mathrm{kg}$ sodium pentobarbital (Sigma-Aldrich; Merck KGaA, Darmstadt, Germany). The right lung was removed at day 4 and snap-frozen in liquid nitrogen for subsequent protein and RNA analysis. Following PBS perfusion of the pulmonary artery, $10 \%$ neutral buffered formalin (Sigma-Aldrich; Merck KGaA) was used to dilate the left lung through the trachea (pressure, $25 \mathrm{~cm} \mathrm{H}_{2} \mathrm{O}$ ) and fixed for $1 \mathrm{~min}$. The trachea was tied and the lungs were removed and fixed in $37 \%$ formalin overnight at $4^{\circ} \mathrm{C}$. Lung tissue samples were subsequently embedded in paraffin and cut into $5 \mu \mathrm{m}$-thick sections and mounted onto glass slides.

Lung histology and morphometry. Lungs (n=6-8/group; hyperoxia or normoxia) were intratracheally fixed with $4 \%$ buffered paraformaldehyde (Sigma-Aldrich; Merck KGaA) overnight at $4^{\circ} \mathrm{C}$ and subsequently embedded in paraffin. Following paraffin embedding and random sectioning, hematoxylin and eosin staining at room temperature for $1 \mathrm{~h}$ was used to quantitatively examine the alveolar region and walls (septal density) in two-three randomly selected lung tissue sections ( $4 \mu \mathrm{m})$ from each mouse. All analyses were performed using a computer-based system (CAST-Grid 2.1.5; Olympus, Ballerup, Denmark). Radial alveolar count (RAC) was examined in $<30$ fields of view in two-three independent random tissue sections from each mouse (18).

Terminal deoxynucleotidyl-transferase-mediated dUTP nick end labeling (TUNEL) analysis of the lung tissue sections was performed using the In Situ Apoptosis Detection kit (Takara Bio, Inc., Otsu, Japan), according to the manufacturer's protocol. The cells were fixed in $37 \%$ formalin overnight at $4^{\circ} \mathrm{C}$ followed by staining with hematoxylin for $30 \mathrm{~min}$ at room temperature. Following hyperoxia exposure for 4 days, the number of TUNEL-positive cells in the pulmonary parenchyma from each mouse was examined in six randomly selected fields under a light microscope. Vectashield antifade mounting medium (Vector Laboratories, Inc., Burlingame, CA, USA) was used for mounting. Five mice were used in the control and experimental groups at each time point. Pulmonary morphology observation was excluded from fields containing cutting defects, conducting airways and large arteries or veins.

Protein extraction and western blot analysis. Following hyperoxia exposure for 4 days, lungs ( $n=4 /$ group) were removed as described above and weighed. Lung tissue samples were stored at $-80^{\circ} \mathrm{C}$ prior to subsequent analysis. Total protein was extracted from lung tissue samples using Halt $^{\mathrm{TM}}$ Protease Inhibitor Cocktail (100X; cat. no. 1861280; Thermo Fisher Scientific, Inc., Waltham, MA, USA) and high urea buffer (KPO4, Urea, AppliChem, Darmstadt, Germany). Total protein was quantified using a bicinchoninic acid assay (cat. no. 23227; Pierce; Thermo Fisher Scientific, Inc.) and $100 \mu \mathrm{g}$ protein/lane was separated via SDS-PAGE on $10 \%$ gel.
The separated protein was transferred onto polyvinylidene fluoride membranes using a Bio-Rad trans-blot SD semi-dry transfer cell (Bio-Rad Laboratories, Inc., Hercules, CA, USA) and blocked for $2 \mathrm{~h}$ at room temperature with blocking buffer containing 5\% skimmed milk. Subsequently, the membranes were incubated with primary antibodies against $\beta$-actin (1:500; cat. no. SC-8432; Santa Cruz Biotechnology, Inc., Dallas, TX, USA), cleaved caspase-8 (cat. no. 3259-100; BioVision Inc., Milpitas, CA, USA), cleaved caspase-6 (cat. no. 9761S) or cleaved caspase-3 (cat. no. 9661; both Cell Signaling Technology, Inc., Danvers, MA, USA) overnight at $4^{\circ} \mathrm{C}$. Following primary incubation, membranes were incubated for $1 \mathrm{~h}$ at room temperature with either goat anti-mouse or donkey anti-goat horseradish peroxidase-labeled secondary antibodies (1:1,000; Dako; Agilent Technologies, Inc., Santa Clara, CA, USA). Protein bands were visualized using the Amersham ECL Prime Western Blotting Detection reagent (cat. no. RPN2232; GE Healthcare Life Sciences, Little Chalfont, UK) and protein expression was quantified using Image Lab software (version 6.0.1; Bio-Rad Laboratories, Inc.).

$R N A$ extraction and reverse transcription-quantitative polymerase chain reaction $(R T-q P C R)$. Total RNA was extracted from lung tissue samples as previously described (19). Total RNA (500 ng) was reverse transcribed into cDNA using the High Capacity cDNA Reverse Transcription kit (Applied Biosystems; Thermo Fisher Scientific, Inc.). qPCR was performed using the TaqMan Universal PCR Master mix (Applied Biosystems; Thermo Fisher Scientific, Inc.) and primers for IL-10, IL-12, monocyte chemoattractant protein (MCP)-1 and TNF- $\alpha$. IL-10 forward, 5'-GCCTAACATGCT TCGAGATC-3- and reverse, 5'-TGATGTCTGGGTCTTGGT TC-3'; IL-12 forward, 5'-ATGTACAGCATGCAGCTCGCA TC-3' and reverse, 5'-GGCTTGTTGAGATGATGCTTTGAC A-3'; MCP-1 forward, 5'-GTCCCTGTCATGCTTCTGG-3' and reverse, 5'-GCGTTAACTGCATCTGGCT-3'; TNF- $\alpha$ forward, 5'-CCCAGGGACCTCTCTCTAATCA-3' and reverse, 5'-AGC TGCCCCTCAGCTTGAG-3'; $\beta$-actin forward, 5'-GTGGGC CGCTCTAGCCACCAA-3' and reverse, 5'-TCTTTGATG TCACGCACGATTTC-3'. qPCR was performed using the Applied Biosystems 7500 FAST Real-Time PCR system (Applied Biosystems; Thermo Fisher Scientific, Inc.). The following thermocycling conditions were used for the qPCR: Initial denaturation for $2 \mathrm{~min}$ at $94^{\circ} \mathrm{C} ; 35$ cycles of $30 \mathrm{sec}$ at $94^{\circ} \mathrm{C}, 30 \mathrm{sec}$ at $58^{\circ} \mathrm{C}$ and $1 \mathrm{~min}$ at $72^{\circ} \mathrm{C}$; final extension for $10 \mathrm{~min}$ at $72^{\circ} \mathrm{C}$. The relative mRNA expression levels were quantified using the comparative critical threshold method and normalized to $\beta$-actin (20).

Cytokine analysis in mouse lung tissue. Mouse tissue-extracted proinflammatory cytokines TNF- $\alpha$, IL-10, IL-12 and MCP-1 were determined in lung tissue samples using the BD $^{\mathrm{TM}}$ Cytometric Bead Array Mouse Inflammation kit (cat. no. 552364; BD Biosciences, San Jose, CA, USA). The samples were analyzed using a BD FACSVerse ${ }^{\mathrm{TM}}$ flow cytometer with C6 software (version 1.0.264.21; BD Biosciences).

Statistical analysis. Data were presented as the mean \pm standard error. All statistical analyses were preformed using SPSS software (version 20; IBM Corporation, Armonk, NY, USA). One-way 
A

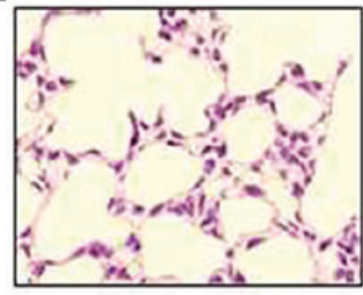

WT normoxia

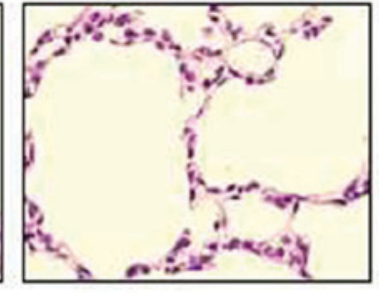

WT hyperoxia

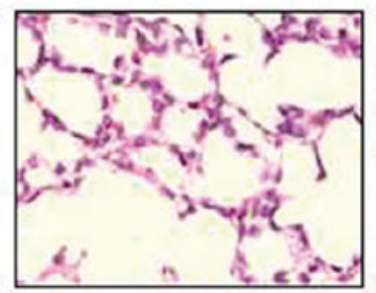

IL-6 ${ }^{-/ *}$ normoxia

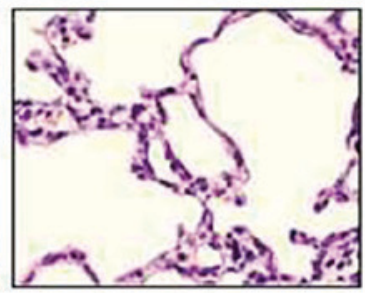

IL-6 ${ }^{-/ 2}$ hyperoxia

B

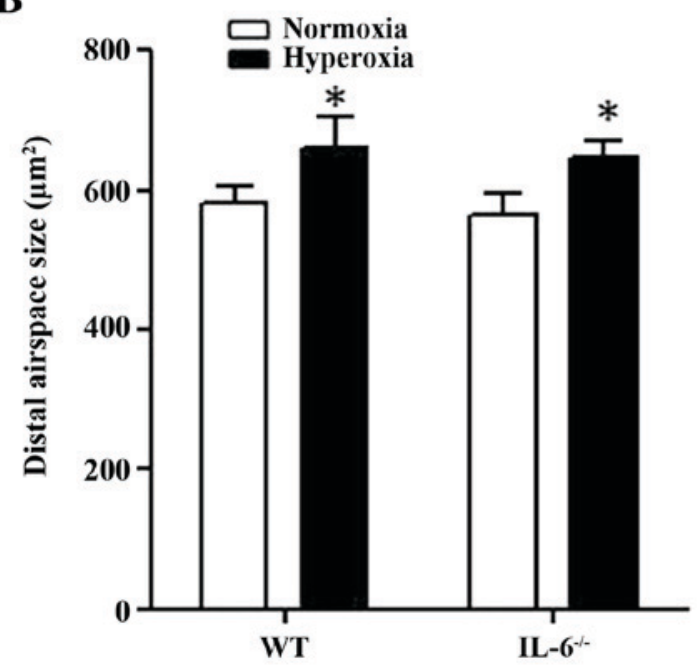

C

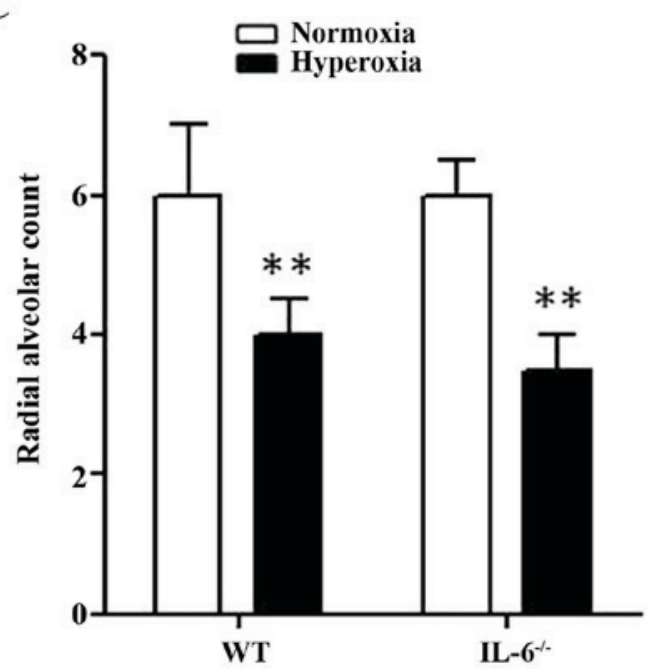

Figure 1. Alveolar development in hyperoxia-exposed mice. (A) Representative lung tissue sections from 4-day old WT and IL-6 null mice exposed to normoxia (room air) or hyperoxia $\left(85 \% \mathrm{O}_{2}\right)$. Magnification, $\mathrm{x} 40$. The alveolar area $(\mathrm{B})$ and the $(\mathrm{C})$ radial alveolar count were examined in 4-day old WT and IL-6 null mice exposed to normoxia or hyperoxia. ${ }^{*} \mathrm{P}<0.05,{ }^{* *} \mathrm{P}<0.01$ vs. normoxia. IL- $6^{-/}$, IL-6 null mice; WT, wild-type; IL, interleukin.

analysis of variance followed by Tukey's post hoc test (for parametric data) or Kruskal-Wallis test (for non-parametric data) was used to analyze differences among multiple groups. $\mathrm{P}<0.05$ was considered to indicate a statistically significant difference.

\section{Results}

Hyperoxia suppresses alveoli development in IL-6 null and WT mice. Histological assessment of lung tissue samples confirmed that IL-6 null and WT mice in the normoxia group developed terminal airways with normal organization. By contrast, the lung structure of IL-6 null and WT mice in the hyperoxia group appeared to be damaged, leading to simplification and dilation of the alveoli (Fig. 1A). The average alveolar airspace size was significantly increased in 4-day old WT and IL-6 null mice in the hyperoxia group compared with the normoxia group (Fig. 1B). In addition, the RAC, which reflects the quantity of alveoli, was significantly decreased in 4-day old WT and IL-6 null mice in the hyperoxia group compared with the normoxia group (Fig. 1C). Furthermore, no significant difference was observed in the alveolar airspace size or the RAC between IL-6 null and WT mice in either the normoxia or hyperoxia group.

Hyperoxia promotes cell apoptosis and pulmonary inflammation in IL-6 null mice. To determine whether IL-6 deficiency augments hyperoxia-induced apoptosis, the TUNEL assay was performed on lung tissue sections from 4-day old IL-6 null and WT mice exposed to normoxia or hyperoxia. The number of TUNEL-positive cells in lung tissue samples was significantly increased in 4-day old WT and IL-6 null mice in the hyperoxia group compared with the normoxia group (Fig. 2A and B). In addition, the number of TUNEL-positive cells was significantly increased in IL-6 null mice compared with WT mice in the hyperoxia group (Fig. 2B). Furthermore, the relative protein expression levels of cleaved caspase- 8 , caspase- 6 and caspase- 3 were increased in IL-6 null mice compared with WT mice in the hyperoxia group (Fig. 2C).

Effects of IL-6 on the production of pro-inflammatory cytokines in hyperoxia-exposed mice. To investigate the role of IL-6 on pulmonary inflammation, mouse tissue-extracted pro-inflammatory cytokines were examined in lung tissue samples from 4-day old IL-6 null and WT mice exposed to normoxia or hyperoxia. The protein expression levels of MCP-1, TNF- $\alpha$, IL-12 and IL-10 were significantly increased in WT and IL-6 null mice in the hyperoxia group compared with the normoxia group (Fig. 3). In addition, the protein levels of pro-inflammatory cytokines were significantly increased in IL-6 null mice compared with WT mice in the hyperoxia group (Fig. 3).

Expression levels of MCP-1, TNF- $\alpha, I L-12$ and $I L-10$ are enhanced in hyperoxia-exposed IL-6 null mice. As the protein expression levels of MCP-1, TNF- $\alpha$, IL-12 and IL-10 were 
$\mathbf{A}$

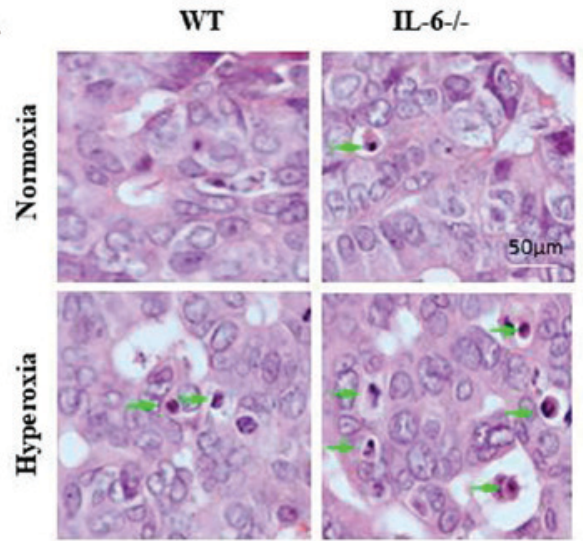

B

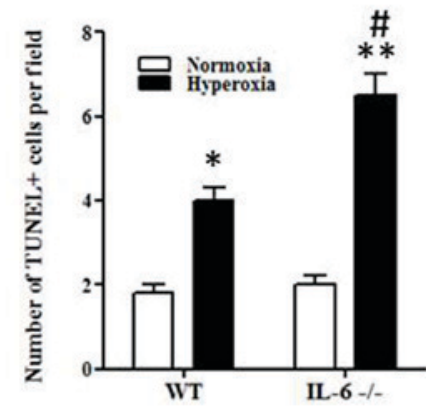

C

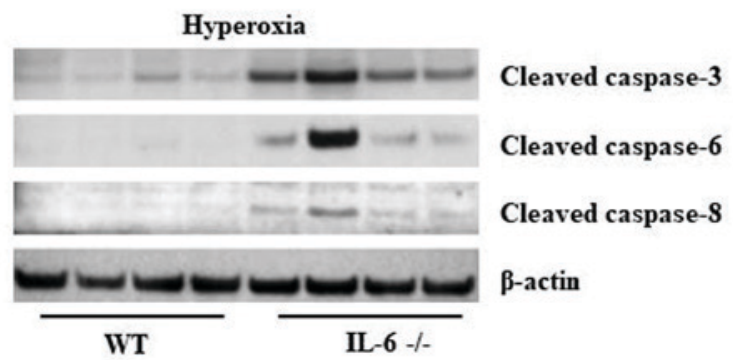

Figure 2. Hyperoxia increases apoptosis in IL-6 null mice. (A) TUNEL staining results from 4-day old WT and IL-6 null mice exposed to normoxia (room air) or hyperoxia ( $85 \%$ oxygen). TUNEL-positive staining was indicated with green arrows. (B) TUNEL-positive cells were examined in 4-day old WT and IL-6 null mice exposed to normoxia or hyperoxia. (C) The relative protein expression levels of cleaved caspase- 8 , caspase- 6 and caspase- 3 was determined by western blot analysis. ${ }^{*} \mathrm{P}<0.05,{ }^{* *} \mathrm{P}<0.01$ vs. normoxia. ${ }^{\#} \mathrm{P}<0.05$ vs. WT. IL-6 ${ }^{-/}$, IL-6 null mice; WT, wild-type; TUNEL, Terminal deoxynucleotidyl-transferase-mediated dUTP nick end labeling; IL, interleukin.

significantly increased in IL-6 null mice compared with WT mice in the hyperoxia group, transcriptional activation of these inflammatory genes was examined in lung tissue samples by RT-qPCR. Similarly, the mRNA expression levels of MCP-1, TNF- $\alpha$, IL-12 and IL-10 were significantly increased in WT and IL-6 null mice in the hyperoxia group compared with the normoxia group (Fig. 4). In addition, MCP-1, TNF- $\alpha$, IL-12 and IL-10 transcription was significantly enhanced in IL-6 null mice compared with WT mice in the hyperoxia group (Fig. 4).

\section{Discussion}

Despite advances in neonatal medicine, BPD remains a major cause of mortality and long-term morbidity in premature infants with a birth weight $<1,000 \mathrm{~g}$ (21-23). As a form of chronic lung disease, BPD arises following OT and MV required for the treatment of acute respiratory distress syndrome (ARDS) in premature infants (24). Pulmonary injury following birth at the terminal canalicular stage can disrupt the normal progression of pulmonary generation, leading to alveolar simplification with larger alveoli, fewer septa and decreased vessel density (25), which can be associated with pulmonary hypertension (26).

IL-6 is a highly versatile cytokine involved in several processes, including cellular proliferation, differentiation and cell death $(8,9)$. Previous studies have demonstrated the importance of IL-6 in several inflammatory pulmonary diseases including ARDS (27), chronic obstructive pulmonary disease (28), non-small cell lung cancer (29) and asthma (30). The effect of IL-6 pre- and post-birth has been investigated following the identification that IL-6 elevation decreases the incidence of respiratory distress syndrome in premature infants (31). In addition, animal models of inflammation inside the amniotic membrane confirmed these results (24). Elevated IL- 6 concentrations were associated with BPD progression, which suggests that upregulated IL- 6 expression may be used as a reliable predictor of BPD progression $(32,33)$. In the current study, IL-6 gene deficiency in pulmonary development treated with hyperoxia enhanced the production of several pro-inflammatory cytokines and cell death. However, treatment with hyperoxia did not promote pulmonary development in neonatal mice.

IL-10 is considered to be an anti-inflammatory cytokine (34). In the current study, the expression level of IL-10 was significantly increased in WT and IL-6 null mice in the hyperoxia group compared with the normoxia group. Protection against hyperoxia may be involved, however, once it fails, apoptosis is automatically triggered and TNF- $\alpha$ is induced to perform its pro-apoptotic function (35). The current study demonstrated that IL-6 deficiency enhanced the expression of TNF- $\alpha$ following exposure to hyperoxia. As a member of the TNF superfamily, TNF- $\alpha$ is one of the most potent inducers of apoptosis (36). TNF- $\alpha$-induced apoptosis is mediated primarily through the activation of type I receptors, the death domain of which recruits multiple signaling proteins, which together form part of an apoptotic cascade. However, further studies are required to determine the mechanisms underlying TNF- $\alpha$-induced apoptosis.

Apoptosis is a form of programmed cell death, which is an essential mechanism to regulate embryonic development and cell differentiation (37). Following treatment with MV in premature babies, apoptosis occurs as a result of oxygen toxicity, septic shock, oxygen deficiency, a decrease in enzymes against oxidants and proteases as well as volutrauma/barotrauma (38). Apoptosis serves an essential role in the degeneration of type II alveolar epithelial cells in adults with ARDS (39). However, type II alveolar epithelial cells exhibit decreased cell death in chronic interstitial pneumonitis (40). Although apoptosis is a prominent event in the lungs of animals injured by inhaling $100 \% \mathrm{O}_{2}$, hyperoxia-induced epithelial cell death occurs as a result of necrosis, and not apoptosis (41).

In the current study, apoptotic cell death occurred in the lungs of neonatal mice exposed to hyperoxia as demonstrated by caspase stimulation and TUNEL staining. Furthermore, loss of IL-6 function through gene ablation enhanced caspase 
A

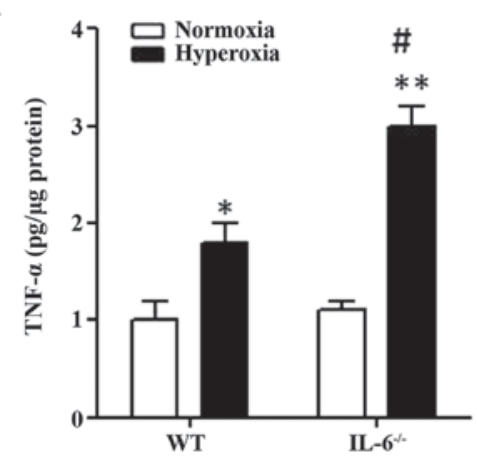

C

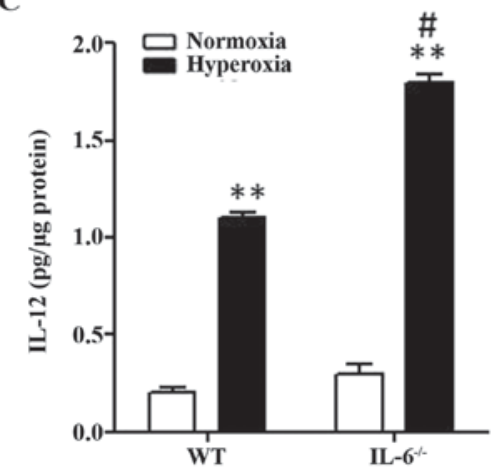

B

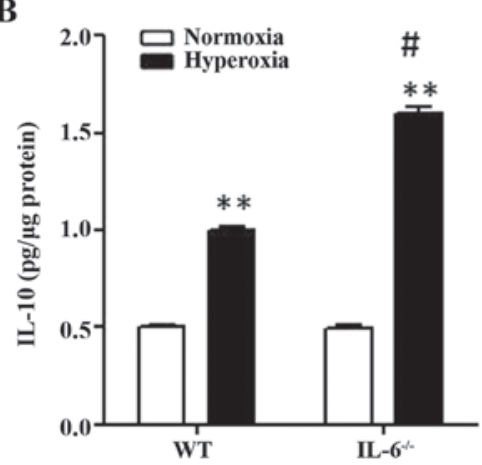

D

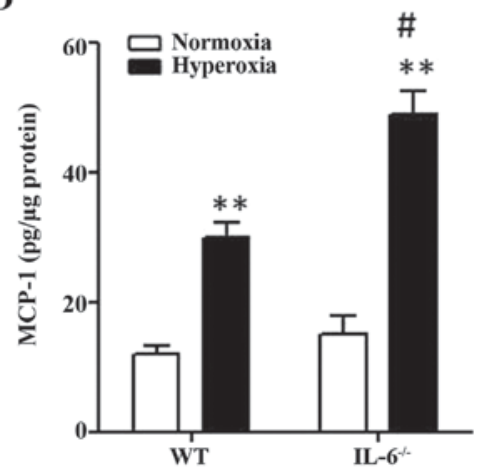

Figure 3. Proinflammatory cytokine protein expression increases in hyperoxia-exposed mice. Mouse tissue-extracted proinflammatory cytokines (A) TNF- $\alpha$, (B) IL-10, (C) IL-12 and (D) MCP-1 were examined in 4-day old WT and IL-6 null mice exposed to normoxia or hyperoxia $(\mathrm{n}=5)$. ${ }^{*} \mathrm{P}<0.05,{ }^{* * *} \mathrm{P}<0.01$ vs. normoxia. ${ }^{~ P}<0.05$ vs. WT. IL-6 ${ }^{-1}$, IL-6 null mice; WT, wild-type; IL, interleukin; TNF, tumor necrosis factor; MCP, monocyte chemoattractant protein.

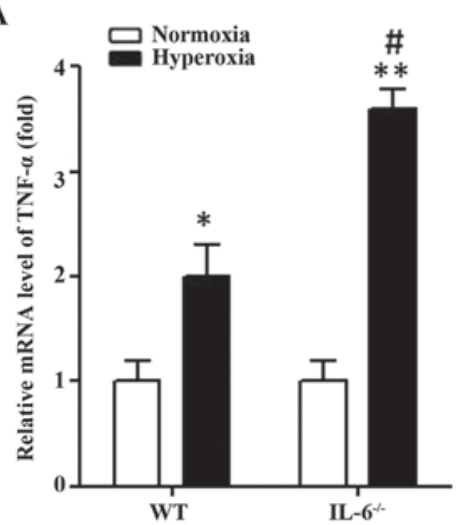

C

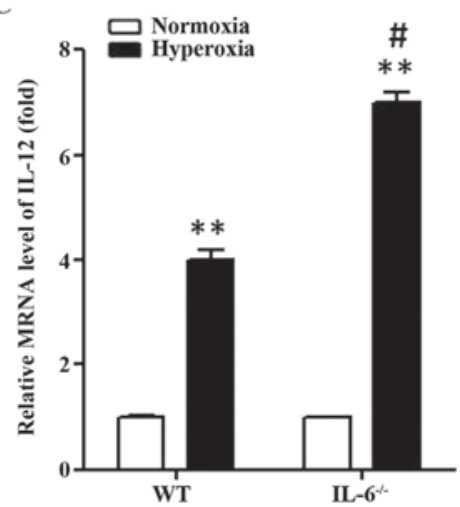

B

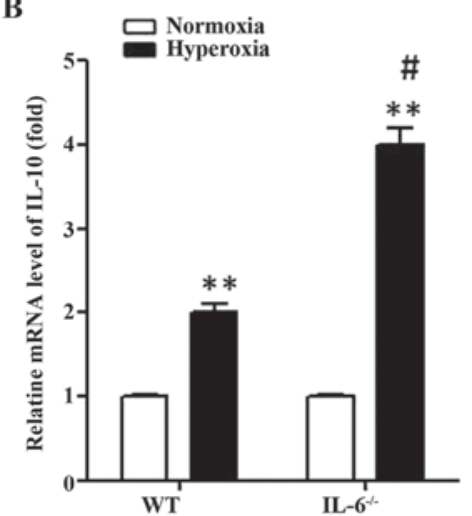

D

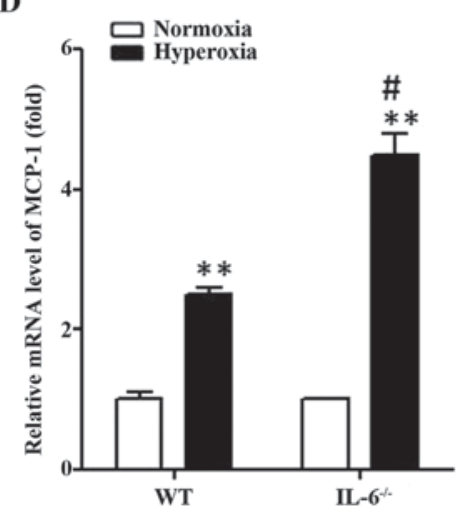

Figure 4. Proinflammatory cytokine mRNA expression increases in hyperoxia-exposed mice. The relative mRNA expression levels of (A) TNF- $\alpha$, (B) IL-10, (C) IL-12 and (D) MCP-1 were determined by reverse transcription-quantitative polymerase chain reaction in lung tissue from 4-day old WT and IL-6 null mice exposed to normoxia or hyperoxia. ${ }^{*} \mathrm{P}<0.05,{ }^{* *} \mathrm{P}<0.01$ vs. normoxia. ${ }^{*} \mathrm{P}<0.05$ vs. WT. IL- $6^{-/}$, IL- 6 null mice; WT, wild-type; IL, interleukin; TNF, tumor necrosis factor; MCP, monocyte chemoattractant protein. 
activation and increased the number of TUNEL-positive cells. These results suggest that the crosstalk between inflammation and cell death may be involved in hyperoxia-induced lung injury in BPD. However, further studies are required to determine whether increased cell death and pulmonary development is linked with poor long-term prognosis.

In conclusion, the current study demonstrated the effect of IL-6 gene deficiency in hyperoxia-induced lung injury. The findings revealed the versatility of IL- 6 as a potentially novel therapeutic approach to attenuate the injury caused by OT and MV.

\section{Acknowledgements}

Not applicable.

\section{Funding}

No funding was received.

\section{Availability of data and materials}

The datasets used and/or analyzed during the current study are available from the corresponding author on reasonable request.

\section{Authors' contributions}

HL contributed to the conception and design of the study and analysis of the results. GW contributed to the design of the study and analysis of the results. SL, CW and JZ performed the experiments, analyzed data, prepared figures and drafted the manuscript. CW approved the final version of the manuscript. JZ edited and revised the manuscript.

\section{Ethics approval and consent to participate}

All procedures and protocols were approved by the Animal Use Committee of Fengcheng Hospital (Shanghai, China).

\section{Patient consent for publication}

Not applicable.

\section{Competing interests}

The authors declare that they have no competing interests.

\section{References}

1. Bhandari A and Panitch HB: Pulmonary outcomes in bronchopulmonary dysplasia. Semin Perinatol 30: 219-226, 2006.

2. Bhandari V: Hyperoxia-derived lung damage in preterm infants. Semin Fetal Neonatal Med 15: 223-229, 2010.

3. Hillman NH, Moss TJ, Kallapur SG, Bachurski C, Pillow JJ, Polglase GR, Nitsos I, Kramer BW and Jobe AH: Brief, large tidal volume ventilation initiates lung injury and a systemic response in fetal sheep. Am J Respir Crit Care Med 176: 575-581, 2007.

4. Woods SJ, Waite AA, O'Dea KP, Halford P, Takata M and Wilson M R: Kinetic profiling of in vivo lung cellular inflammatory responses to mechanical ventilation. Am J Physiol Lung Cell Mol Physiol 308: L912-L921, 2015.
5. Yoon BH, Romero R, Jun JK, Park KH, Park JD, Ghezzi F and Kim BI: Amniotic fluid cytokines (interleukin-6, tumor necrosis factor-alpha, interleukin-1 beta, and interleukin-8) and the risk for the development of bronchopulmonary dysplasia. Am J Obstet Gynecol 177: 825-830, 1997.

6. Bry K and Lappalainen U: Pathogenesis of bronchopulmonary dysplasia: The role of interleukin 1beta in the regulation of inflammation-mediated pulmonary retinoic acid pathways in transgenic mice. Semin Perinatol 30: 121-128, 2006.

7. Speer CP: Pulmonary inflammation and bronchopulmonary dysplasia. J Perinatol 26 (Suppl 1): S57-S64, 2006.

8. Dame JB and Juul SE: The distribution of receptors for the pro-inflammatory cytokines interleukin (IL)-6 and IL-8 in the developing human fetus. Early Hum Dev 58: 25-39, 2000.

9. Xing Z, Gauldie J, Cox G, Baumann H, Jordana M, Lei XF and Achong MK: IL-6 is an antiinflammatory cytokine required for controlling local or systemic acute inflammatory responses. J Clin Invest 101: 311-320, 1998.

10. Jaskoll T and Melnick M: Submandibular gland morphogenesis: Stage-specific expression of TGF-alpha/EGF, IGF, TGF-beta, TNF, and IL-6 signal transduction in normal embryonic mice and the phenotypic effects of TGF-beta2, TGF-beta3, and EGF-r null mutations. Anat Rec 256: 252-268, 1999.

11. Melnick M, Chen H, Zhou YM and Jaskoll T: Interleukin-6 signaling and embryonic mouse submandibular salivary gland morphogenesis. Cells Tissues Organs 168: 233-245, 2001.

12. Jobe AH and Ikegami M: Antenatal infection/inflammation and postnatal lung maturation and injury. Respir Res 2: 27-32, 2001.

13. Zhao L, Hart S, Cheng J, Melenhorst JJ, Bierie B, Ernst M, Stewart C, Schaper F, Heinrich PC, Ullrich A, et al: Mammary gland remodeling depends on gp130 signaling through Stat 3 and MAPK. J Biol Chem 279: 44093-44100, 2004.

14. Culig Z, Steiner H, Bartsch G and Hobisch A: Interleukin-6 regulation of prostate cancer cell growth. J Cell Biochem 95: 497-505, 2005.

15. Thebaud B and Abman SH: Bronchopulmonary dysplasia: Where have all the vessels gone? Roles of angiogenic growth factors in chronic lung disease. Am J Respir Crit Care Med 175: 978-985, 2007.

16. Berger J and Bhandari V: Animal models of bronchopulmonary dysplasia. The term mouse models. Am J Physiol Lung Cell Mol Physiol 307: L936-L947, 2014.

17. Fukumoto J, Fukumoto I, Parthasarathy PT, Cox R, Huynh B, Ramanathan GK, Venugopal RB, Allen-Gipson DS, Lockey RF and Kolliputi N: NLRP3 deletion protects from hyperoxia-induced acute lung injury. Am J Physiol Cell Physiol 305: C182-C189, 2013.

18. Emery JL and Mithal A: The number of alveoli in the terminal respiratory unit of man during late intrauterine life and childhood. Arch Dis Child 35: 544-547, 1960.

19. Ito M, Nagano N, Arai Y, Ogawa R, Kobayashi S, Motojima Y, Go H, Tamura M, Igarashi K, Dennery PA and Namba F: Genetic ablation of Bach1 gene enhances recovery from hyperoxic lung injury in newborn mice via transient upregulation of inflammatory genes. Pediatr Res 81: 926-931, 2017.

20. Livak KJ and Schmittgen TD: Analysis of relative gene expression data using real-time quantitative PCR and the 2(-Delta Delta C(T)) method. Methods 25: 402-408, 2001.

21. Vohr BR, Wright LL, Dusick AM, Mele L, Verter J, Steichen JJ, Simon NP, Wilson DC, Broyles S, Bauer CR, et al: Neurodevelopmental and functional outcomes of extremely low birth weight infants in the National Institute of Child Health and Human Development Neonatal Research Network, 1993-1994. Pediatrics 105: 1216-1226, 2000.

22. Lemons JA, Bauer CR, Oh W, Korones SB, Papile LA, Stoll BJ, Verter J, Temprosa M, Wright LL, Ehrenkranz RA, et al: Very low birth weight outcomes of the National Institute of Child health and human development neonatal research network, January 1995 through December 1996. NICHD Neonatal Research Network. Pediatrics 107: E1, 2001.

23. Allen J, Zwerdling R, Ehrenkranz R, Gaultier C, Geggel R, Greenough A, Kleinman R, Klijanowicz A, Martinez F, Ozdemir A, et al: Statement on the care of the child with chronic lung disease of infancy and childhood. Am J Respir Crit Care Med 168: 356-396, 2003.

24. Jobe AH and Bancalari E: Bronchopulmonary dysplasia. Am J Respir Crit Care Med 163: 1723-1729, 2001.

25. Beers MF and Mulugeta S: The biology of the ABCA3 lipid transporter in lung health and disease. Cell Tissue Res 367: 481-493, 2017. 
26. Mourani PM, Ivy DD, Gao D and Abman SH: Pulmonary vascular effects of inhaled nitric oxide and oxygen tension in bronchopulmonary dysplasia. Am J Respir Crit Care Med 170: 1006-1013, 2004.

27. Bhatia $\mathrm{M}$ and Moochhala S: Role of inflammatory mediators in the pathophysiology of acute respiratory distress syndrome. J Pathol 202: 145-156, 2004.

28. Doganci A, Sauer K, Karwot R and Finotto S: Pathological role of IL-6 in the experimental allergic bronchial asthma in mice. Clin Rev Allergy Immunol 28: 257-270, 2005.

29. Chung KF: Cytokines in chronic obstructive pulmonary disease. Eur Respir J (Suppl 34): S50-S59, 2001.

30. Bihl M, Tamm M, Nauck M, Wieland H, Perruchoud AP and Roth M: Proliferation of human non-small-cell lung cancer cell lines: Role of interleukin-6. Am J Respir Cell Mol Biol 19: 606-612, 1998

31. Shimoya K, Taniguchi T, Matsuzaki N, Moriyama A, Murata Y, Kitajima H, Fujimura M and Nakayama M: Chorioamnionitis decreased incidence of respiratory distress syndrome by elevating fetal interleukin-6 serum concentration. Hum Reprod 15: 2234-2240, 2000.

32. Kramer BW, Kramer S, Ikegami M and Jobe AH: Injury, inflammation, and remodeling in fetal sheep lung after intra-amniotic endotoxin. Am J Physiol Lung Cell Mol Physiol 283: L452-L459, 2002.

33. Moss TJ, Newnham JP, Willett KE, Kramer BW, Jobe AH and Ikegami M: Early gestational intra-amniotic endotoxin: Lung function, surfactant, and morphometry. Am J Respir Crit Care Med 165: 805-811, 2002.

34. Saraiva M and O'Garra A: The regulation of IL-10 production by immune cells. Nat Rev Immunol 10: 170-181, 2010.
35. Liu Y, Jiang W, Liu S, Su X and Zhou S: Combined effect of tnf-alpha polymorphisms and hypoxia on steroid-induced osteonecrosis of femoral head. Int J Clin Exp Pathol 8: 3215-3219, 2015.

36. Micheau $\mathrm{O}$ and Tschopp J: Induction of TNF receptor I-mediated apoptosis via two sequential signaling complexes. Cell 114: 181-190, 2003.

37. Qu X, Zou Z, Sun Q, Luby-Phelps K, Cheng P, Hogan RN, Gilpin C and Levine B: Autophagy gene-dependent clearance of apoptotic cells during embryonic development. Cell 128: 931-946, 2007.

38. Hargitai B, Szaboó V, Hajdú J, Harmath A, Pataki M, Farid P, Papp Z and Szende B: Apoptosis in various organs of preterm infants: Histopathologic study of lung, kidney, liver, and brain of ventilated infants. Pediatr Res 50: 110-114, 2001.

39. Korfei M, Ruppert C, Mahavadi P, Henneke I, Markart P, Koch M, Lang G, Fink L, Bohle RM, Seeger W, et al: Epithelial endoplasmic reticulum stress and apoptosis in sporadic idiopathic pulmonary fibrosis. Am J Respir Crit Care Med 178: 838-846, 2008.

40. Bardales RH, Xie SS, Schaefer RF and Hsu SM: Apoptosis is a major pathway responsible for the resolution of type II pneumocytes in acute lung injury. Am J Pathol 149: 845-852, 1996.

41. Kazzaz JA, Xu J, Palaia TA, Mantell L, Fein AM and Horowitz S: Cellular oxygen toxicity. Oxidant injury without apoptosis. J Biol Chem 271: 15182-15186, 1996.

This work is licensed under a Creative Commons Attribution-NonCommercial-NoDerivatives 4.0 International (CC BY-NC-ND 4.0) License. 